\title{
Computação, Educação, Gênero e Diversidade: discussões e perspectivas futuras
}

\author{
Leander C. de Oliveira1, Carolina M. Oliveira², Leonam C. Oliveira ${ }^{2}$ \\ ${ }^{1}$ Programa de pós-graduação em Tecnologia e Sociedade (PPGTE) - Universidade \\ Tecnológica Federal do Paraná (UTFPR) - Curitiba - PR - Brasil \\ ${ }^{2}$ Departamento de Informática - Universidade Federal do Paraná (UFPR) \\ Curitiba - PR - Brasil \\ \{leanderdeoliveira, carolmoliveiraa, leonamcdeoliveira\}@gmail.com
}

Abstract. Gender discussions in Computing have grown, but with approaches that are strongly linked to female representation issues. With gender studies deepening and its third wave discussions, it is important to understand the power relations that underlie these constructions and, in this way, to involve other subalternated and/or marginalized groups that emerge in this process.

Resumo. As discussões de gênero na Computação tem crescido, mas com abordagens que estão fortemente ligadas às questões da representatividade feminina. Com o aprofundamento dos estudos de gênero e suas discussões de terceira onda, surge a importância de compreender as relações de poder que estão por trás destas construções e, desta forma, envolver outros grupos subalternizados elou marginalizados que emergem neste processo.

\section{Os Estudos de Gênero em uma Perspectiva Pós-Identitária}

Há alguns anos, observa-se o crescimento de estudos que discutem as questões de representação de gênero na área da Computação. Em especial, estes estudos tratam de recortes de gênero específicos, discutindo a participação das mulheres. Ainda que as perspectivas sejam diversas no que diz respeito ao envolvimento destas com a Computação, tanto no uso de tecnologias educacionais, quando em seu desenvolvimento e nos processos formativos em diferentes níveis de ensino, de forma bastante geral a discussão está voltada a uma perspectiva identitária, uma vez que se pretende a trabalhar mais especificamente as problematizações relacionadas às mulheres [Castelini, 2018; Oliveira e Amaral, 2019].

O crescimento deste movimento têm revelado importantes relações dentro da área da Computação, em seus processos de ensino e aprendizagem, desenvolvimento, uso, dentre outros. Relações estas que dizem respeito a uma área que, alinhada também a perspectivas que estão presentes na formação em áreas tecnológicas de forma geral, como nas engenharias, por exemplo, se constrói normativa [Wajcman, 2010]. Discutir a diversidade dentro da Computação e suas subáreas, como a Informática na Educação, passa a ser um caminho necessário e que levanta muitos desafios. Ao aprofundar a discussão sobre as questões de gênero na área, torna-se imprescindível abordar as relações de poder que estão relacionadas. Butler (2017) traz em sua teoria, apontamentos que desvelam as relações de gênero e sexualidade, compreendendo-as como construções que são constantemente reiteradas aos sujeitos a partir da cultura e 
dos processos sociais, que se fazem presentes em todas as esferas da vida, inclusive em campos de saber, como é o caso da Computação, e em processos educativos.

A partir destas reflexões, é importante compreender que o fazer científico e tecnológico passa diretamente pela construção das subjetividades, uma vez que os valores dos sujeitos são trazidos neste processo e acabam incorporados em suas construções no mundo [Wajcman, 2010]. Uma área que se constrói por determinado tipo de sujeito, que tem construções identitárias muito similares, passa a se tornar desinteressante para diversos grupos sociais que escapam desta realidade. Processos estes que passam diretamente pelos ambientes educativos da Computação e também da crescente influência que a área tem recebido na educação, de forma mais geral.

Construir discussões que envolvam grupos marginalizados e/ou subalternizados, como populações migrantes, indígenas, quilombolas, LGBTTQIAs, mulheres dentre outras, é um desafio latente e que diz respeito à participação, ao envolvimento e a apropriação destas pessoas na construção da Computação. Mais profundamente, ainda, dizem respeito a compreender as relações de poder que estão permeadas pela área e as delimitações consequentes deste processo [Oliveira e Amaral, 2019].

A educação, quando compreendida em seu potencial transformador, é um campo que precisa se envolver diretamente nesta discussão e, talvez mais do que isso, ser uma das protagonistas de um processo de repensar as clivagens sociais que marcam determinados grupos, colocando-os em situações de marginalização e subalternidade [Louro, 2016]. Merkle (2020) faz uma relação entre o computar com as discussões de Freire em seu livro pedagogia da autonomia, construindo o que chamou de informática da autonomia. Destacam-se em seu texto as discussões de que o "computar exige respeito aos saberes de participantes e trabalhadores", o "computar exige criticidade", o "computar exige risco, aceitação do novo e rejeição a qualquer forma de discriminação" [Merkle, 2020 p. 6]. O autor traz para a reflexão esta concepção de computar como uma computação que acontece a partir de fazeres, saberes e quereres humanos como forma de lembrar que a área faz parte dos contextos sociais, surgindo, como qualquer tecnologia, da construção humana sobre o mundo. Neste processo, absorve os valores de quem a cria e, consequentemente, os reproduz.

Entendendo o poder de processos educativos nas esferas da computação e, mais especificamente sobre os processos formativos, é preciso sempre considerar o contexto dos estudantes para que os processos de aprendizagem sejam significativos, trabalhando de forma que exista aproximação em relação às realidades e os conteúdos e temáticas abordadas [Ortiz et al., 2018]. Pensar a Computação relacionada com processos educativos de forma a questionar suas normatividades internas, mas também as suas ligações com o mundo e os sujeitos é um processo de reflexão crítica e imprescindível para que seja possível superar tais construções e pensar em uma computação aberta e diversa.

\section{Agradecimentos}

O presente trabalho foi realizado com apoio da Coordenação de Aperfeiçoamento de Pessoal de Nível Superior - Brasil (CAPES) - Código de Financiamento 001. 


\section{Referências}

Butler, Judith. (2017). Problemas de Gênero: feminismo e subversão da identidade. 13 ed. Tradução de Renato Aguiar. Rio de janeiro: Civilização Brasileira.

Castelini, Pricila. (2018). Mulheres na Computação: percepções, memórias e participação de estudantes e egressas. 2018. 133 f. Dissertação (Mestrado em Tecnologia e Sociedade) - Universidade Tecnológica Federal do Paraná, Curitiba. Disponível em <http://repositorio.utfpr.edu.br/jspui/handle/1/2944>.

Louro, Guacira Lopes. (2016). Uma Política Pós-identitária para a Educação e "Estranhar" o Currículo. In: Louro, Guacira Lopes. Um Corpo Estranho - Ensaios sobre sexualidade e Teoria Queer. 2ed. Belo Horizonte: Autêntica.

Merkle, Luiz Ernesto (2020). Não há computação sem suputares: valores necessários ao poder, ao fazer, ao querer e ao saber computar. In: Barbosa e Silva, Rodrigo e Blikstein, Paulo (orgs). Robótica Educacional: experiências inovadoras na educação brasileira. Porto Alegre: Penso. ISBN 978-85-8429-188-5

Oliveira, Leander C. de e Amaral, Marília Abrahão (2019). Espaços do Computar: O Hacker e Maker em uma perspectiva Queer. In: Martins, Ernane Rosa (org). Fundamentos da Ciência da Computação. Ponta Grossa: Atena Editora. ISBN 978-85-7247-157-2.

Ortiz, J. S. B., Oliveira, C. M., e Pereira, R. (2018). Aspectos do Contexto Sociocultural dos Alunos estão Presentes nas Pesquisas para Ensinar Pensamento Computacional? Em Anais dos Workshops do Congresso Brasileiro de Informática na Educação, volume 7, page 520.

Wajcman, Judy. (2010) Feminist Theories of Technology. Cambridge Journal of Economics, v. 34, e. 1. P. 143-152. Doi: https://doi.org/10.1093/cje/ben057. 